\title{
Editorial
}

\section{Personalised price}

Journal of Revenue and Pricing Management (2016) 15, 1. doi:10.1057/rpm.2015.52

Revenue Management ( $R M$ ) has always been about allocating the right capacity to the right customer at the right price at the right time. Fundamentally maximising value and price for a specific time period. In today's world of sophisticated data science holds the promise of perfect price discrimination, that is, individuated transactions in which the customer decides to make a purchase and make it at the highest price he or she is willing to pay. Cultures across the Western world and beyond are now showing many examples and experiments in the arena of personalisation. Just as product content can be cut and customised to suit the individual shopper or traveller so price can be equally well tailored. Price can also be adjusted to reflect contingent human situations (in a hurry? in a jam? in a shifting mood? in an experimental state of mind?...) and /or exploit ever expanding and ever more actionable shopping histories, all captured in vast corporate reservoirs of Big Data.

Many in the public policy community are aligned with consumerist lobbies in being at least suspicious of (if not directly hostile to) personalised pricing - seeing something dangerously Orwellian in this whole evolution. But even though personalisation may be in its haltingly experimental stages in much of general retail, its progress is bound to accelerate across the rest of this decade. Nothing can really interrupt its forward march. The notion of personalised pricing for an airline ticket, a bet, a hotel room or a round of golf is here.

Brand leaders must keep two interactive themes in their minds, personalised products and personalised prices. In addition, they have to track how the presence of multiple payment methods and indeed currencies can influence the shape of personalised pricing. As customers get used to paying in different ways, so there may well be, on occasions, more than one personalised price available to them. Personalised pricing is a story of rising consumer expectation. As personalised benefits are enjoyed in one theatre (for example, holiday travel) so they will increasingly be demanded in others (for example, household durables). No sector will be immune from the tightening consumer belief that the whole shopping experience should be me-shaped. Though personalised pricing may meet early resistance, it will popularise very quickly (Future Foundation, 2015).

The attributes of personalised pricing include:

- The persistence of price sensitivity even in the wealthiest economies where household revenues are growing

- The sheer sophistication of predictive analytics machinery and the devotion to Big Data being expressed within marketing spend

- The slowly emerging comfort that millions will soon feel in relation to wearable technology and the focus on individual lifestyle management which is implied

- The ever increasing product volumes which are bought online - and not in-store - with conventional, invisible cash

- The swelling value to corporate profitability of dynamic pricing: optimising price in relation to a customer's location, the channel she is using, the timing of her click

\section{REFERENCE}

Future Foundation (2015) My Price, https://nvision.future foundation.net/, accessed 21 December 2015.

Ian Yeoman

Editor

E-mail: ian.yeoman@vuw.ac.nz 